\title{
DETERMINATION OF THE OCCURRENCE FREQUENCY OF CRYPTOSPORIDIUM SP. IN CHILDREN BROUGHT TO THE HOSPITAL WITH THE COMPLAINT OF DIARRHEA USING DIFFERENT METHODS
}

\author{
EKICI, A. ${ }^{1 *}-$ ÜNLÜ, A. H. ${ }^{2}-$ HALIDI, A. G. ${ }^{3}-$ AYDEMIR, S. $^{1}-$ YILMAZ, H. ${ }^{1}$ \\ ${ }^{I}$ Department of Parasitology, Faculty of Medicine, Van Yuzuncu Yil University, Van, Turkey \\ ${ }^{2}$ Veterinary Division, Gevaş Vocational School, Van Yuzuncu Yil University, Van, Turkey \\ ${ }^{3}$ Bulanık Vocational School, Muş Alparslan University, Muş, Turkey \\ *Corresponding author \\ e-mail: abdurrahman2400@gmail.com
}

(Received $19^{\text {th }}$ Dec 2020; accepted $14^{\text {th }}$ May 2021)

\begin{abstract}
Cryptosporidium is a parasite responsible for diarrhea in humans. Practitioners rarely routinely request Cryptosporidium diagnostic tests; thus, its prevalence is likely underrated. The prevalence of cryptosporidiosis among children brought to the hospital with the complaint of diarrhea was investigated using 3 different methods, comprising nested PCR, immunochromatographic testing, and microscopic examination with modified acid-fast staining. Cryptosporidium sp. was detected in 42/150 children with diarrhea $(28 \%)$ and in $1 / 50$ children in the control group (2\%). The main complaint by children admitted to hospital with Cryptosporidium was diarrhea. Additionally, some clinical symptoms/signs like abdominal pain, nausea, vomiting, stool mucus, weakness, weight loss, and anorexia were correlated with cryptosporidiosis. Results from the 3 methods were compared and nested PCR and immunochromatographic testing were the most reliable. Among other pathogens and parasites found in stool samples, Cryptosporidium is a significant cause of hospitalization due to gastrointestinal disease in children in Van, Turkey.
\end{abstract}

Keywords: cryptosporidiosis, children, diarrhea, immunochromatographic test, nested PCR

\section{Introduction}

Diarrhea is a significant cause of morbidity and mortality for children worldwide, especially for children under 5 years of age. According to the World Health Organization, more than 1.3 billion cases of diarrhea per year have been reported in children under the age of 5 in Asia, Africa, and Latin America. Approximately 4 million children have died in this age range, $80 \%$ of whom were in their first 2 years of life. Diarrhea accounts for $21 \%$ of all deaths in children under 5 years of age in developing countries (Çakmur, 2013). Considering the prevalence of diarrhea in Turkey for the 0-6-year-old age group, the incidence of diarrhea in children has been reported as 32.3\% (Şantaş, 2019).

Diarrhea is a symptom of infection caused by bacterial, viral, or parasitic factors that are taken into the body, often as a result of consuming water contaminated with feces. Bacteria and parasites play the biggest role in acute gastroenteritis in developing countries. The most common agents of acute parasitic gastroenteritis can be listed as Giardia intestinalis, Cryptosporidium sp., Entamoeba histolytica, and Dientamoeba fragilis. Mass epidemics of Cryptosporidium species have been recorded (Usluca et al., 2019). Although diarrhea causes malnutrition and growth retardation, it can also cause death in severe cases. Diarrhea, the etiology of which has not been determined, is of great importance due to the unnecessary use of antibiotics or antimicrobials (Brintz et al., 2020). 
The disease caused by Cryptosporidium sp. is called cryptosporidiosis. Cryptosporidiosis is a zoonotic infection caused by prototypes of the genus Cryptosporidium in mammals, reptiles, poultry, and fish. Cryptosporidiosis is a common disease that causes diarrhea in humans and pets worldwide. Specifically in underdeveloped or developing countries, it is more common in people whose immune systems are suppressed and malnourished. The agent is transmitted by fecal oral route. There are many factors that affect the epidemiology of cryptosporidiosis. Only a few oocysts are necessary to cause an infection. They can remain alive for a long time, are resistant to many disinfectants, and are infective when discarded from the host. Animals can be reservoirs for some genotypes, while their hosts remain immune. In humans, 7 species of Cryptosporidium (C. parvum, C. hominis, C. meleagridis, C. felis, C. canis, $C$. suis, and $C$. muris) cause disease; however, $C$. parvum and $C$. hominis were detected in most of the outbreaks and cases that have been reported (Özcel et al., 2007).

The diagnosis of the disease is based on the microscopic examination of oocysts that are excreted with feces. For this, some staining methods should be used. However, these methods have disadvantages in cases where the oocyst amount is low, such that the factor can be overlooked; hence, it requires experienced staff, and preparation and inspection processes require time. For these reasons, there is a need to use immunochromatographic, serological, and molecular methods that provide more reliable results (Korkmaz and Ok, 2011; Özcel et al., 2007).

In the case of diarrhea due to cryptosporidiosis, it is known that severe clinical pictures can occur as a result of fluid electrolyte imbalance, and chronic diarrhea negatively affects the growth and development of children. Moreover, considering that diarrhea can lead to malnutrition, it is of great importance to investigate the factors that cause diarrhea in childhood.

In this study, the occurrence frequency of Cryptosporidium $s p$. in children brought to the hospital with the complaint of diarrhea was determined using three different methods. The determination of the role of the modified acid-fast staining technique, which is the standard used in the diagnosis of cryptosporidiosis; the immunochromatographic test method, which is easy to use in laboratories; and the nested PCR method, which has been noted to have significant advantages, in addition to the sensitivity and specificity of the disease in diarrhea, were investigated.

\section{Materials and methods}

This study was carried out between April 2020 and June 2020 at the Parasitology Laboratory of Van Yüzüncü Y1l University Dursun Odabasi Medical Center. The study was conducted on stool samples of children under the age of 18 who had diarrhea. A total of 200 stool samples were collected from 150 children who had diarrhea, regardless of sex, and 50 healthy children without symptoms as a control group. The sex, age, general condition of the patient, and clinical findings were recorded for each sample collected. The modified acid-fast (Korkmaz and Ok, 2011) and immunochromatographic test (CerTest Biotek, Spain) methods were applied to the stool samples.

The GeneMATRIX stool DNA purification kit (EURx Ltd., Gdansk, Poland) was used for DNA extraction, which was performed in accordance with the instructions provided with the kit. However, before starting the purification procedures, the samples 
were incubated at $95{ }^{\circ} \mathrm{C}$ for $30 \mathrm{~min}$ in a dry block heater (Bio-TDB-100, BioSan) at 5 min intervals in order to effectively weaken the oocyst wall.

The nested PCR method was used for the molecular investigation. First, primers CryptoF 5'-TTCTAGAGCTAATACATGCG-3' and CryptoR 5'CCCATTTCCTTCGAAACAGGA-3' were used, which amplified the DNA fragment, encoding the SSU rRNA as 1.325 bp in length (Sakarya et al., 2010). For the PCR reaction, $25 \mu \mathrm{L}$ of Solis Biodyne 5X Firepol (12.5 $\mathrm{mM} \mathrm{MgCl}_{2}$ ) master mix was used, which comprised $100 \mathrm{nM}$ of each primer and $2 \mu \mathrm{L}$ of the sample DNA, and $1 \mu \mathrm{L}$ of these reaction products was later subjected to the nested PCR. During the nested PCR, a base set of CryptoNF 5'- GGAAGGGTTGTATTTATTAGATAAAG-3' and CryptoNR 5'- AAGGAGTAAGGAACAACCTCCA-3' was used, which amplified a region about 826-864 bp in length (Sakarya et al., 2010).

The reactions were performed in a thermo thermal cycler with a heater lid (SimpliAmp Thermal Cycler, Thermo Fisher). The first step of the PCR consisted of a total of 18 cycles $\left(33 \mathrm{~s}\right.$ at $95^{\circ} \mathrm{C}, 45 \mathrm{~s}$ at $55^{\circ} \mathrm{C}$, and $45 \mathrm{~s}$ at $72^{\circ} \mathrm{C}$ ), and a 10 -min extension period at $72{ }^{\circ} \mathrm{C}$. The second step of the PCR was performed the same as the first step, but with an annealing process that comprised 35 cycles.

PCR products were run for $45 \mathrm{~min}$ at $90 \mathrm{~V}$ in $1 \%$ agarose gel with ethidium bromide, and the images were recorded. From the pool with positive results, 10 samples were randomly selected and subjected to sequence analysis, which confirmed Cryptosporidium $\mathrm{sp}$.

In this study, the chi square test was used to determine the relationship between the categorical variables. Odds values were calculated for the risk rates of the parasites. Sensitivity and specificity values were found to determine the success criteria of the methods used. Statistical significance was accepted as $\mathrm{P}<0.05$ and Minitab 17 statistical software (State College, PA, USA) was used for the calculations.

\section{Results}

In this study, Cryptosporidium sp. was detected in 42 of the 150 children with diarrhea (28\%) and 1 of the 50 children in the control group (2\%).

When the results obtained via the immunochromatographic test and the modified acid-fast staining methods were compared with the results obtained via the nested PCR method, a statistically significant difference was found between them $(\mathrm{P}<0.05$; Table 1). Herein, the samples identified as positive with the modified acid-fast staining method (Fig. 1) were also identified as positive with the immunochromatographic test (Fig. 2) and the nested PCR method (Fig. 3). However, 12 samples that were identified as negative with the modified acid-fast staining method were identified as positive with the other 2 methods. The modified acid-fast staining method used in this study identified the sensitivity as $71.4 \%$ and specificity as $100 \%$ (Table 1). It was observed that the immunochromatographic test method, which offers much more practical and faster results, and works with the antigen scanning principle in the stool, was a lot more sensitive than the modified acid-fast staining method. The sensitivity and specificity were 100\%, and the same results were obtained with the nested PCR method (Table 1).

In children infected with cryptosporidiosis, abdominal pain $(\mathrm{P}=0.0001)$, nausea ( $\mathrm{P}=0.0001)$, vomiting $(\mathrm{P}=0.0001)$, stool mucus $(\mathrm{P}=0.0001)$, weakness $(\mathrm{P}=0.0001)$, weight loss $(\mathrm{P}=0.0001)$, and anorexia $(\mathrm{P}=0.001)$ were found and the statistical evaluation showed significant relationships between cryptosporidiosis and these 


$$
-2908 \text { - }
$$

symptoms, separately (Table 2). However, no statistically significant results were found between cryptosporidiosis and sex, constipation, the presence of other parasites, fever, leukocytes, or age.

Table 1. Detected sensitivity and specificity values of the modified acid-fast staining, immunochromatographic test, and nested PCR methods

\begin{tabular}{c|c|c|c}
\hline Values & $\begin{array}{c}\text { Modified acid-fast } \\
\text { staining (\%) }\end{array}$ & $\begin{array}{c}\text { Immunochromatographic } \\
\text { test (\%) }\end{array}$ & Nested PCR (\%) \\
\hline Sensitivity & 71.4 & 100.0 & 100.0 \\
Specificity & 100.0 & 100.0 & 100.0 \\
False negativity rate & 28.6 & 100.0 & 100.0 \\
False positivity rate & 0.0 & 0.0 & 0.0 \\
Undetectable positivity & 28.6 & 0.0 & 0.0 \\
Negative prediction value & 90.0 & 100.0 & 100.0 \\
Positive estimation value & 100.0 & 100.0 & 100.0 \\
Accuracy rate & 92.0 & 100.0 & 100.0 \\
\hline
\end{tabular}

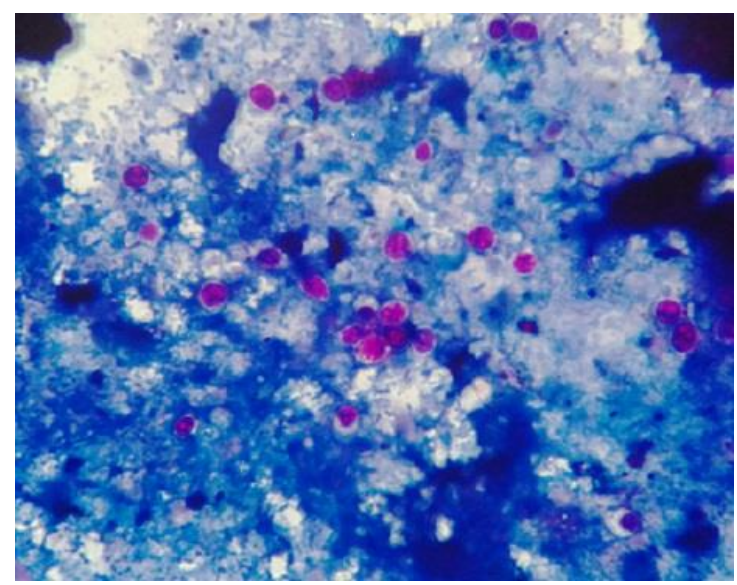

Figure 1. Microscopic image of Cryptosporidium sp. oocysts using the modified acid-fast staining method (1000X)

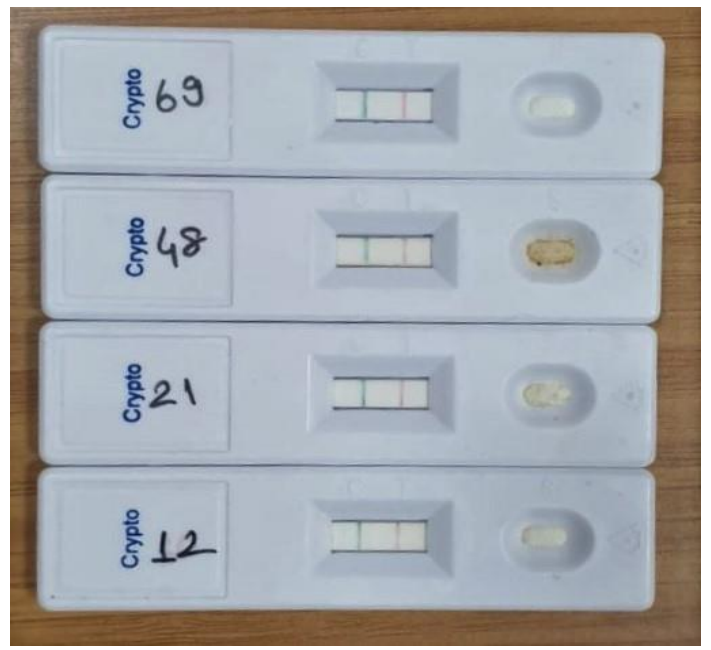

Figure 2. Samples identified as positive using the immunochromatographic test method 


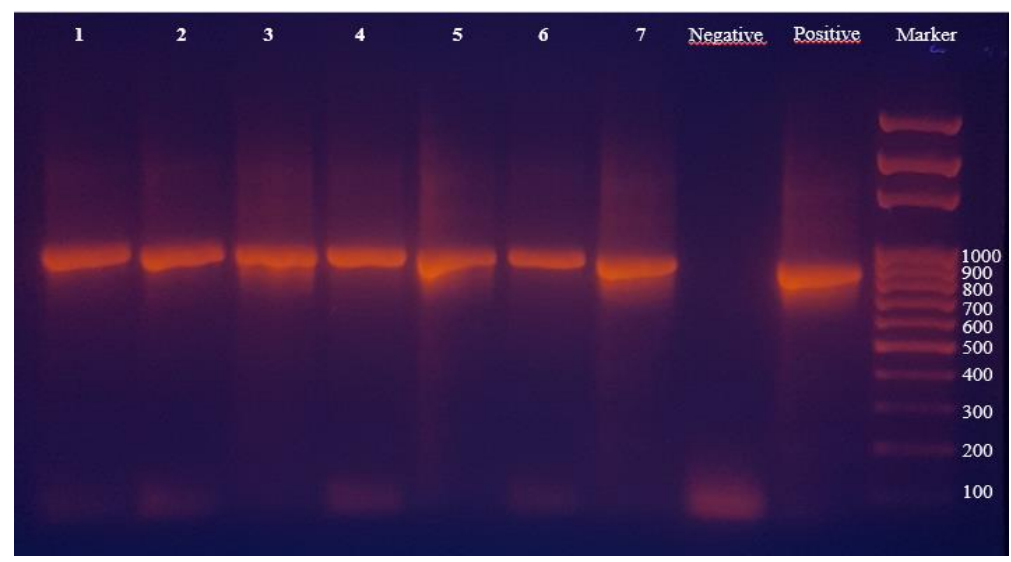

Figure 3. Agarose gel image of the amplification of the 826-864 bp region of Cryptosporidium sp. via the nested PCR method (Marker: Brand Origin DNA ladder, negative: negative control, positive: positive control, positive examples: 1-7)

Table 2. Relationship between the frequency of Cryptosporidium and some clinical symptoms

\begin{tabular}{|c|c|c|c|c|c|}
\hline \multirow{2}{*}{\multicolumn{2}{|c|}{ Clinical signs and symptoms }} & \multicolumn{2}{|c|}{ Cryptosporidium sp. } & \multirow{3}{*}{$\begin{array}{c}\text { Total }(\mathbf{1 0 0 \%}) \\
31\end{array}$} & \multirow[b]{2}{*}{ P-value } \\
\hline & & \multirow{2}{*}{$\begin{array}{c}\begin{array}{c}\text { Positive } \\
\text { (number and \%) }\end{array} \\
24(77.4)\end{array}$} & \multirow{2}{*}{\begin{tabular}{|c|}
$\begin{array}{c}\text { Negative } \\
\text { (number and \%) }\end{array}$ \\
$7(22.6)$ \\
\end{tabular}} & & \\
\hline \multirow{2}{*}{ Vomiting } & $\begin{array}{c}\text { Positive } \\
\text { (number and \%) }\end{array}$ & & & & \multirow{2}{*}{0.0001} \\
\hline & $\begin{array}{c}\text { Negative } \\
\text { (number and \%) }\end{array}$ & $18(15.1)$ & $101(84.9)$ & 119 & \\
\hline \multirow{2}{*}{ Nausea } & $\begin{array}{c}\text { Positive } \\
\text { (number and \%) }\end{array}$ & $30(71.4)$ & $12(28.6)$ & 42 & \multirow{2}{*}{0.0001} \\
\hline & $\begin{array}{c}\text { Negative } \\
\text { (number and \%) }\end{array}$ & $12(11.1)$ & $96(88.9)$ & 108 & \\
\hline \multirow{2}{*}{ Weakness } & $\begin{array}{c}\text { Positive } \\
\text { (number and \%) }\end{array}$ & $27(75)$ & $9(25)$ & 36 & \multirow{2}{*}{0.0001} \\
\hline & $\begin{array}{c}\text { Negative } \\
\text { (number and \%) }\end{array}$ & $15(12.2)$ & $99(79.8)$ & 124 & \\
\hline \multirow{2}{*}{ Anorexia } & $\begin{array}{c}\text { Positive } \\
\text { (number and \%) }\end{array}$ & $15(51.7)$ & $14(48.3)$ & 29 & \multirow{2}{*}{0.001} \\
\hline & $\begin{array}{c}\text { Negative } \\
\text { (number and \%) }\end{array}$ & $27(22.3)$ & $94(77.7)$ & 121 & \\
\hline \multirow{2}{*}{ Abdominal pain } & $\begin{array}{c}\text { Positive } \\
\text { (number and \%) }\end{array}$ & $36(81.8)$ & $8(18.2)$ & 44 & \multirow{2}{*}{0.0001} \\
\hline & $\begin{array}{c}\text { Negative } \\
\text { (number and \%) }\end{array}$ & $8(7.5)$ & $98(92.5)$ & 106 & \\
\hline \multirow{2}{*}{ Weight loss } & $\begin{array}{c}\text { Positive } \\
\text { (number and \%) }\end{array}$ & $32(76.2)$ & $10(2.4)$ & 42 & \multirow{2}{*}{0.0001} \\
\hline & $\begin{array}{c}\text { Negative } \\
\text { (number and \%) }\end{array}$ & $9(8.3)$ & 99 (91.7) & 108 & \\
\hline \multirow{2}{*}{ Mucus } & $\begin{array}{c}\text { Positive } \\
\text { (number and \%) }\end{array}$ & $27(81.8)$ & $6(18.2)$ & 33 & \multirow{2}{*}{0.0001} \\
\hline & $\begin{array}{c}\text { Negative } \\
\text { number and \%) }\end{array}$ & $15(12.8)$ & $102(87.2)$ & 117 & \\
\hline
\end{tabular}




\section{Discussion}

Cryptosporidium infections have been observed all over the world, especially in developing countries. Patients with a strong immune system respond to this infection with humoral and cellular immunity. Although cryptosporidiosis is not taken into consideration in clinical examinations, it can cause fatal diarrhea, especially in immunosuppressed patients. When the immune system is suppressed for any reason, a suitable environment is created for the reproduction and development of parasites in the gastrointestinal tract, thereby resulting in malabsorption. Specifically in severe infections, fluid loss has been reported to increase to 10-15 L per day in adults and up to $5 \mathrm{~L}$ in a 14-month-old child (Menon et al., 1999). It has been stated that transmission is more frequent in crowded environments, such as nurseries, hospitals, and nursing homes, and the infection is more common in children than in adults (Börekçi et al., 2005).

Cryptosporidiosis has attracted attention due to the fact that this parasite can be transmitted through water and cause refractory diarrhea, especially in patients with immune deficiency; hence, many studies have been conducted on this protozoon to date (Çiçek and Yılmaz, 2011). It can cause fatal diarrhea in immunosuppressed patients, as well as diarrhea in children, resulting in severe fluid loss, electrolyte imbalance, and even circulatory failure in advanced cases. Diagnosis of cryptosporidiosis cannot be made merely through clinical examinations of patients. Therefore, ineffective and longterm treatments are usually attempted. For this reason, the patient is given unnecessary medication, and as a result of incorrect treatment, the patient cannot be treated, and the situation becomes more serious. In addition, due to the unnecessary and ineffective use of medications, the economy of the country will be damaged. For this reason, when an assessment is made regarding both the protection of the health of a patient and harm to the economy of a country, the use of rapid diagnostic tests for the determination of Cryptosporidium sp. becomes better understood.

Lethal diarrhea in children under the age of 24 months is mostly caused by rotavirus (Clark et al., 2017), which may be controlled by vaccination programs (Clark et al., 2017). This is closely followed by Cryptosporidium sp., one of the most widely found parasites in humans (Mmbaga and Houpt, 2017). Cryptosporidium-related diarrhea in children may cause malnutrition, disrupted physical and cognitive development, and even death. The response to treatments has been variable, and a vaccination is not yet available. For this reason, it is important to identify methods that can effectively demonstrate the existence of Cryptosporidium species, are inexpensive and have high accuracy, and can prove their effectiveness. A prevalence study of Cryptosporidium among children conducted by Shaposhnik et al. (2019) showed that, regarding the methods for identification of the positive samples, $100 \%$ were identified via RT-PCR, $88 \%$ were identified via antigen test, and only $67 \%$ were identified via microscopic examination with acid-fast staining. Considering the results obtained in the current study, the sensitivity and specificity obtained from the nested PCR and immunochromatographic test results were $100 \%$.

The disadvantages of the modified acid-fast dyeing method are the need for experienced personnel, the low probability of encountering the agent when the amount of oocyst is low, and the time required for preparation and examination processes. The biggest advantage of this method is that it is cheap and applicable. The routine use of PCR method for detecting Cryptosporidium sp. in laboratories is very important in terms of obtaining better results, since Cryptosporidium species can be identified even 
from a small number of oocysts by PCR method. In addition, the immunochromatographic test method can be recommended to be used in all laboratories due to the ease of use, its rapid results in diagnosing cryptosporidiosis, high detection ability and its low cost.

Many studies on cryptosporidiosis have been conducted in children, and different rates of prevalence have been found in these studies. In a study of children with diarrhea in Egypt, 8.5\% of 1050 patients were identified as positive for Cryptosporidium sp. via the modified acid-fast staining method (El et al., 2007). A study conducted in the southwest region of Cameroon revealed an overall prevalence of $8.9 \%$ for Cryptosporidium sp. among children aged 0-5 years (Tombang et al., 2019). Stool specimens were processed using the modified acid-fast staining method only. The prevalence among children who presented with diarrhea was $13.4 \%$. A study conducted in the United States on children with normal immune systems and no symptoms reported the prevalence of Cryptosporidium sp. as 6.4\% (Hunter and Nichols, 2002). In another study, it was shown that the rate of Cryptosporidium sp. in asymptomatic children under the age of 5 was 4.7\% (Al Braiken et al., 2003). In the current study, Cryptosporidium sp. was detected in only 1 of the 50 children in the control group (2\%).

Cryptosporidium sp. was found in $25.2 \%$ of 135 children $(91.9 \%$ of whom were $\leq 5$ years of age) who applied to a hospital in Malaysia with various complaints other than HIV and were diagnosed using the modified Ziehl Neesen method (Asady et al., 2019). A study on children in Iran showed that socioeconomic factors and nutritional status were related to the incidence of Cryptosporidium sp. and the severity of the disease (Madadi et al., 2020). In obtaining this result, better molecular methods, such as loopmediated isothermal amplification and nested PCR, were used. In general, when considering the diagnostic methods used in studies on Cryptosporidium sp. worldwide, it can be seen that traditional methods, such as modified acid-fast, are the most used. In choosing these methods, since molecular methods contain stages such as DNA extraction, PCR kit, and gel electrophoresis, it can be expensive and require the skills of an experienced researcher.

Some studies have been performed on cryptosporidiosis in children in Turkey and obtained different results. In a study conducted in Ankara, Cryptosporidium sp. was found in $4 \%$ of children (Doganci et al., 2002). Cryptosporidium sp. was found in $4.5 \%$ of patients in a study conducted on 178 children aged 0-6 in Van (Beyhan and Y1lmaz, 2020). In a study conducted in Istanbul, Cryptosporidium sp. was found in $2.50 \%$ of 480 patients, including adults and children with diarrhea, and $9.50 \%$ of children under 3 years of age (Över, 1997). In the present study, Cryptosporidium sp. was found in $28 \%$ of 150 children with diarrhea. This result was determined as statistically significant and it was generally higher than the results obtained in studies on children with diarrhea (Över, 1997; Doganci et al., 2002; Üner et al., 1991). The low socioeconomic status, insufficient infrastructure, and widespread animal husbandry in the Van region of Turkey are among the reasons that the prevalence is higher there than in other regions. As a result, the importance of conducting research on cryptosporidiosis is once again understood, especially for children, who suffer from diarrhea the most, in places where the socioeconomic status is low, the infrastructure is insufficient, and breeding is common.

During 2010 and 2011, two important outbreaks occurred due to Cryptosporidium hominis, which affected 2 cities in Sweden. The symptoms in the people included weight loss, diarrhea, abdominal pain, joint pain, loss of appetite, and fatigue (Rehn et 
al., 2015). In that study, abdominal pain $(P=0.0001)$, nausea $(P=0.0001)$, vomiting $(\mathrm{P}=0.0001)$, weakness $(\mathrm{P}=0.0001)$, and weight loss $(\mathrm{P}=0.0001)$, and anorexia $(\mathrm{P}=0.001)$ were observed in people infected with cryptosporidiosis and the statistical evaluation revealed significant relationships between cryptosporidiosis and these symptoms, separately. For this reason, although diarrhea is the first symptom to be considered in cryptosporidiosis (Özcel et al., 2007), it was concluded that this factor should be kept in mind if one or more of the symptoms, such as abdominal pain, nausea, vomiting, stool mucus, weakness, weight loss, or anorexia, are observed.

In this study, the prevalence of Cryptosporidium sp. in children who applied to the hospital with complaints of diarrhea was determined using 3 different methods. In this way, while determining the effectiveness of the methods used, it was also ensured that the relationship of some disease symptoms with the parasite was statistically revealed.

\section{Conclusion}

In conclusion, using the molecular diagnosis, immunochromatographic test, and microscopic examination together on the stool samples revealed that there was a higher prevalence of Cryptosporidium sp. infection among children with diarrhea admitted to the Van YYU Dursun Odabas Medical Center. The present study highlighted the importance of testing for Cryptosporidium sp. among children with diarrheal diseases. Moreover, conducting both the molecular diagnosis and the immunochromatographic test could further enhance the precision and sensitivity of the diagnosis of Cryptosporidium sp. In addition, due to the high rates obtained in the current study, it was concluded that Cryptosporidium sp. should be considered in cases of childhood diarrhea. It was concluded that further studies should be carried out on Cryptosporidium sp., which is one of the important diarrhea agents in children, since childhood diarrhea can be life-threatening.

\section{REFERENCES}

[1] Al Braiken, F., Amin, A., Beeching, N., Hommel, M., Hart, C. A. (2003): Detection of Cryptosporidium amongst diarrhoeic and asymptomatic children in Jeddah, Saudi Arabia. - Annals of Tropical Medicine Parasitology 97: 505-510.

[2] Asady, A., Ismail, S., Marsitah, A., Pakeer, O. (2019): Prevalence of Cryptosporidium sp. infection among children admitted to Hospital Tengku Ampuan Afzan. - The Medical Journal of Malaysia 74: 468-471.

[3] Beyhan, Y. E., and Y1lmaz, H. (2020): Investigation of Cryptosporidium spp. antigen by ELISA in stool specimens: nine year evaluation. - Turkish Journal of Parasitology 44(2): 68-71.

[4] Börekçi, G., Otăg, F., Emekdaş, G. (2005): The prevalence of Cryptosporidium in families in a slum district of Mersin, Turkey. - Turkish Journal of Infection 19: 39-46.

[5] Brintz, B. J., Howard, J. I., Haaland, B., Platts-Mills, J. A., Greene, T., Levine, A. C., Leung, D. T. (2020): Clinical predictors. - Tropical Diseases 14(10): 8677.

[6] Çakmur, H. (2013): Infectious diarrhea and dehydration in childhood. - Kafkas Journal Medical Science 3(2): 96-102.

[7] Çiçek, M., Yılmaz, H. (2011): Prevalence of Cryptosporidium spp. and other intestinal parasites in children with diarrhea. - Dicle Medical Journal 38: 70-75.

[8] Clark, A., Black, R., Tate, J., Roose, A., Kotloff, K., Lam, D., Blackwelder, W., Parashar, U., Lanata, C., Kang, G. (2017): Estimating global, regional and national rotavirus deaths 
in children aged $<5$ years: current approaches, new analyses and proposed improvements. - PloS One 12.

[9] Doganci, T., Araz, E., Ensari, A., Tanyuksel, M., Doganci, L. (2002): Detection of Cryptosporidium parvum infection in childhood using various techniques. - Medical Science Monitor 8: 223-226.

[10] El, A. S., Soltan, D., El-Sheikha, H., Sadek, G., Morsy, A. (2007): Correlation of ELISA copro-antigen and oocysts count to the severity of Cryptosporidiosis parvum in children. - Journal of the Egyptian Society of Parasitology 37: 107-120.

[11] Hunter, P. R., Nichols, G. (2002): Epidemiology and clinical features of Cryptosporidium infection in immunocompromised patients. - Clinical Microbiology Reviews 15: 145154.

[12] Korkmaz, M., Ok, Ü. (2011): Parazitolojide laboratuvar. - Türkiye Parazitoloji Derneği, İzmir.

[13] Madadi, S., Mahami-Oskouei, M., Rafeey, M., Spotin, A., Aminisani, N., MahamiOskouei, L., Ghoyounchi, R., Berahmat, R. (2020): Comparative evaluation of Cryptosporidium infection in malnourished and well-nourished children: parasitic infections are affected by the interaction of nutritional status and socio-demographic characteristics. - Comparative Immunology, Microbiology and Infectious Diseases 68: 101406.

[14] Menon, B. S., Abdullah, M., Mahamud, F., Singh, B. (1999): Brief report. Intestinal parasites in Malaysian children with cancer. - Journal of Tropical Pediatrics 45: 241-242.

[15] Mmbaga, B. T., Houpt, E. R. (2017): Cryptosporidium and Giardia infections in children: a review. - Pediatric Clinics 64: 837-850.

[16] Över, U. (1997): The role of Cryptosporidium in diarrheal dissease. - Flora 2: 98-104.

[17] Özcel, M. A., Özbel, Y., Ak, M. (2007): Özcel'in tıbbi parazit hastalıkları. - Türkiye Parazitoloji Derneği, İzmir.

[18] Rehn, M., Wallensten, A., Widerström, M., Lilja, M., Grunewald, M., Stenmark, S., Kark, M., Lindh, J. (2015): Post-infection symptoms following two large waterborne outbreaks of Cryptosporidium hominis in Northern Sweden, 2010-2011. - BMC Public Health 15: 529-535.

[19] Sakarya, Y., Kar, S., Tanyüksel, M., Karaer, Z., Babur, C., Vatansever, Z. (2010): Detection of Cryptosporidium sp. in humans and calves through nested PCR and carbol fuchsin staining methods in Ankara, Turkey. - Kafkas Univ Vet Fak Derg 16: 977-980.

[20] Şantaş, F. (2019): Prevalence of diarrhea in children under five and distribution by basic features in Turkey. - Journal of Ankara Health Sciences 8: 127-137.

[21] Shaposhnik, E. G., Abozaid, S., Grossman, T., Marva, E., On, A., Azrad, M., Peretz, A. (2019): The prevalence of Cryptosporidium among children hospitalized because of gastrointestinal symptoms and the efficiency of diagnostic methods for Cryptosporidium. - The American Journal of Tropical Medicine and Hygiene 101: 160-163.

[22] Tombang, A. N., Ambe, N. F., Bobga, T. P., Nkfusai, C. N., Collins, N. M., Ngwa, S. B., Diengou, N. H., Cumber, S. N. (2019): Prevalence and risk factors associated with cryptosporidiosis among children within the ages $0-5$ years attending the Limbe regional hospital, southwest region, Cameroon. - BMC Public Health 19: 1144-1154.

[23] Usluca, S., Berberoğlu, A. E. E., Çelebi, B., Kılıç, S. (2019): Method verification study for detection of Cryptosporidium spp. by realtime PCR method. - Journal of Turkish Microbiology Society 49(3): 162-168. 